\title{
Encephalopathy, deafness and blindness in young women: a distinct retinocochleocerebral arteriolopathy?
}

\author{
JULIEN BOGOUSSLAVSKY,* JEAN-MARC GAIO,$\dagger$ LOUIS R CAPLAN, $\ddagger$ \\ FRANCO REGLI, * MARC HOMMEL, $\dagger$ THOMAS R HEDGES III, \\ MARCO FERRAZZINI, * PIERRE POLLAK $\dagger$
}

From the Departments of Neurology, Centre Hospitalier Universitaire Vaudois, Lausanne, Switzerland, ${ }^{*}$ Centre Hospitalier Régional et Universitaire, Grenoble, France, $\dagger$ and New England Medical Center Hospitals, Boston, Massachusetts, USA

SUMMARY Three young women (aged 18 years, 19 years and 19 years) who developed progressive neuropsychic and neurologic disturbances with hearing loss and multifocal retinal artery branch occlusions are reported. This retinocochleocerebral syndrome has been reported previously only in 12 young North American women. Its pathogenesis is unknown, but an atypical viral infection of the vessel walls has been suggested. Abnormalities of $\mathrm{T}$ lymphocytes subsets in blood in one of the patients suggested an immunological dysfunction, but all other tests, including immunological reactions on brain and skin biopsies, were negative or non-specific. Steroids and immunosuppressive agents have been advocated on an empirical basis, but the second patient showed a substantial recovery without any therapy and the third gradually deteriorated despite azathioprine, cyclophosphamide, prednisone and plasma exchanges. This retinocochleocerebral syndrome probably corresponds to an arteriolopathy of unknown nature.

A syndrome of encephalopathy, hearing loss and retinal arteriolar occlusions has been reported in 12 young North American women over the last 15 years..$^{1-6}$ We report two European patients with this condition, as well as another North American patient.

\section{Case reports}

Patient 1. A 18 year old woman was referred to the Lausanne University Department of Neurology because of memory loss, insomnia, bulimia, dizziness and visual blurring, which developed over 4 months. Her general physical condition was normal. Blood pressure was $110 / 50 \mathrm{~mm} \mathrm{Hg}$. Her gait was moderately ataxic, but the rest of the neurological examination was normal. The patient showed perseverations and was disorientated in time. The CSF was clear, with 2 lymphocytes $/ \mathrm{ml}$, normal glucose $(3.1 \mathrm{mmol} / \mathrm{l}$, plasma glucose $4.1 \mathrm{mmol} / \mathrm{l})$ and increased proteins $(1.590 \mathrm{~g} / \mathrm{l})$ with no oligoclonal banding and normal IgG index. CSF

Address for reprint requests: Dr J Bogousslavsky, Department of Neurology, CHUV, 1011 Lausanne, Switzerland

Received 11 March 1988 and in revised form 8 August 1988. Accepted 26 August 1988 myelin basic protein was increased $(4.8 \mathrm{mg} / \mathrm{l})$. Brain CT with and without contrast, MRI, cerebral panangiography, visual somatosensory and auditory evoked potentials and EMG studies were normal. Erythrocyte sedimentation rate (ESR) was $40 \mathrm{~mm} / \mathrm{h}$. Blood lymphocytes subsets were abnormal (Leu $7=4 \cdot 3 \quad(N=18 \cdot 1, \quad S D 2 \cdot 1)$, Leu 3a/Leu 2a ratio $=2.43(2 \cdot 16$, SD $0 \cdot 14))$, but all other biological and immunological investigations were normal, including blood count, liver function tests, partial thromboplastin time, prothrombin time, serum protein electrophoresis, thyroid function tests, anti-Ro, anti-RNP and ANA level, rheumatoid factor, anti HIV antibodies, syphilis tests (VDRL, FTA, TPHA, TPI), serum IgG, IgA, IgM, $C_{3}, C_{4}$. Cardiopulmonary auscultation, chest radiographs and ECG were normal. The patient's condition worsened over 2 weeks, with apathy, confusion, urinary incontinence, increased tendon reflexes with left-sided Babinski and marked ataxia. Ophthalmoscopic examination showed retinal oedema, irregularities of peripheral retinal arterioles with segmental obstructions (fig 1). On fluorescein angiography, periarteriolar exudation was noted. A brain biopsy was done in the right frontal cortex and showed moderate gliosis with neuronal loss suggesting chronic hypoxic changes. No inflammatory infiltrate was present. The blood vessels were slightly thickened but showed no fibrosis, hyalinosis or amyloid deposit. Reaction with anti-IgG, IgA, IgM and kappa and lambda chains antisera was negative. A skin 


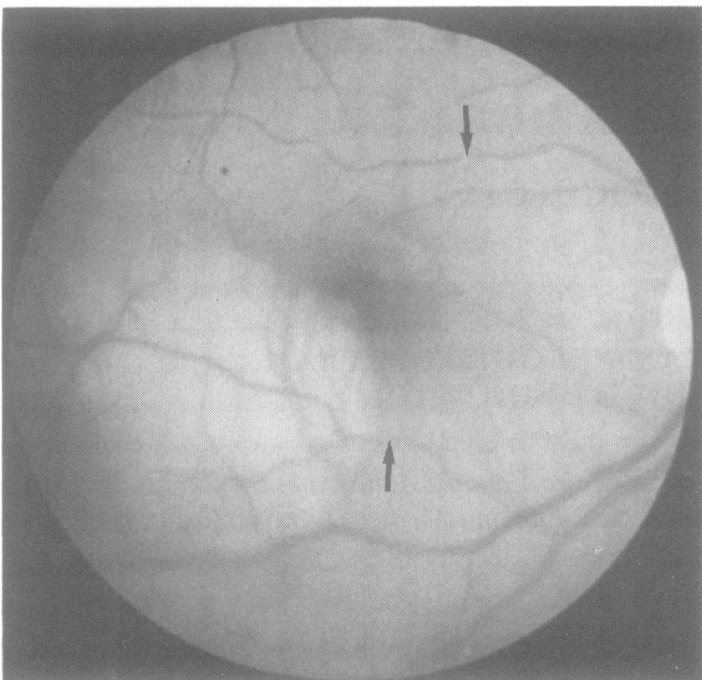

Fig 1 Patient 1. Right optic fundus. Whitish submacular oedema with arteriolar occlusion (arrows).

biopsy specimen was normal, with a negative reaction with anti-IgG, IGA, IgM, $\mathrm{C}_{3}$ and fibrin antisera. Prednisone 80 $\mathrm{mg}$ /day was started with a progressive improvement, and was decreased over 3 months, with a maintenance dosage of 20 $\mathrm{mg} /$ day. Pure-tone audiometry showed a left-sided sensorineural hearing loss from 3,000 to $8,000 \mathrm{~Hz}$. Brain CT showed developing cerebral atrophy. Azathioprine $150 \mathrm{mg} /$ day was introduced and prednisone was stopped over 10 months. The patient improved progressively over 2 years, being able to work three half-days per week as a secretary. Left hearing loss, ataxia, and bilateral corticospinal dysfunction signs persisted.

Patient 2. A 19 year old woman was admitted to Grenoble University Hospital, because of headaches associated with loss of visual acuity in the left eye, confusion, and unsteady gait, which had developed over 3 weeks. Her general examination was normal. Blood pressure was 110/ $70 \mathrm{~mm}$ Hg. Neurological examination disclosed a moderate faciobrachial motor deficit. Visual acuity was $4 / 10$ in the left eye and 10/10 in the right eye. Ophthalmoscopy showed segmental obstructions of the retinal arterioles, periarteriolar exudations and areas of retinal infarction (fig 2). She showed perseverations, and was disorientated in time and place. Tendon reflexes were brisk with bilateral Babinski sign. She was ataxic and incontinent for urine. She could distinguish sounds, but oral language was not understood. Brainstem auditory evoked potentials (BAEP) showed no abnormality. Four days later, hearing dysfunction worsened. Audiometry showed a bilateral and severe hearing loss from 500 to 8,000 Hz. No response was noted on brainstem auditory evoked potentials. CSF was clear, with 2 lymphocytes/ml and increased proteins $(880 \mathrm{mg} / \mathrm{l})$. IgG index was normal with no oligoclonal banding. Standard blood and urine tests were normal. ESR was $8 \mathrm{~mm} / \mathrm{h}$. Serum IgM raised to $3 \mathrm{~g} / \mathrm{l}$ (normal:

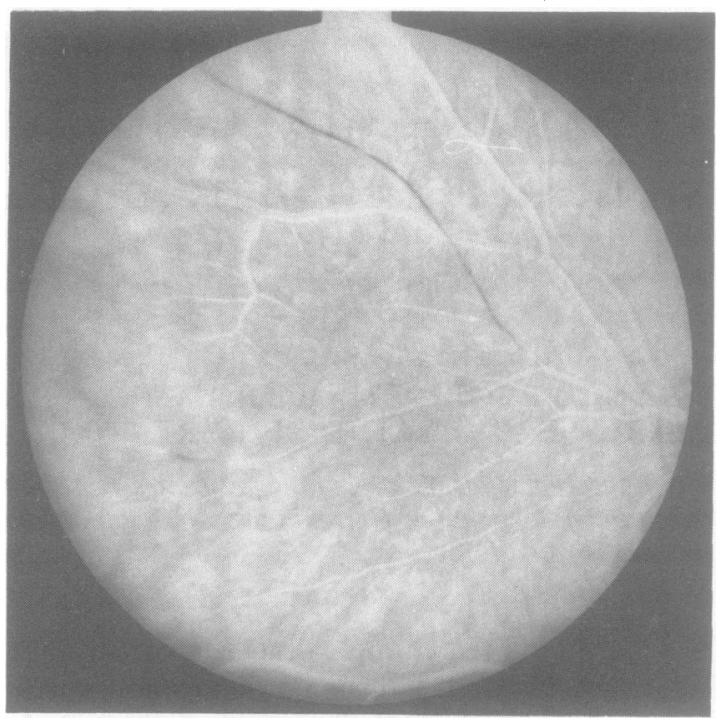

Fig 2 Patient 2. Fluorescein angiography in the left eye showing distal arteriolar sheething and occlusions (dark areas in vessels).

0.6-1) with no monoclonal fraction, and returned to normat within 3 weeks. Serum IgG and IgA remained normat Immunological investigations showed no modification? including anti-RNP and ANA, $C_{3}, C_{4}$, immunocytologic study of lymphocytes, syphilis tests (TPHA, VDRL). Live? and thyroid function tests, bacterial blood cultures, vira serology including anti-HiV antibodies were normal. A skif biopsy specimen was normal with negative immunofluores cence reactions. ECG, brain CT and cerebral panangiogras phy were normal. The patient's condition worsened over $z^{2}$ weeks and then improved progressively. Methylprednisolone $80 \mathrm{mg} / \mathrm{day}$ had no effect and was discontinued after 2 months. Four months later, MRI showed small areas of high signal in both hemispheres throughout the white matter (fig 3). Thirty months later, the patient was able to work as a bookkeeper. Neurologic examination showed only moderate cerebellar ataxia and brisk reflexes on the left side. Ophthalmoscopy and audiometry remained unchanged.

Patient 3. From age 19 years, this patient developed over 5 years poor vision, frontal headaches, staggering gait, decrease in hearing and slurred speech. In the past she had used dextro-amphetamine diet pills and occasionally injected heroin intravenously. At age 26, she was first hospitalised in Boston. On examination, she had decreased spontaneity and replied slowly. Memory was poor. Visual acuity was slightly reduced (20/20-2 OD, 20/20-3 OS). Visual fields showed an inferior altitudinal defect in the left eye and a superior nasal defect in the right eye. The optic discs were grey and arteries were markedly attenuated and sheathed and some arteries near the disc were occluded. Hearing was diminished bilaterally. Jaw and limb deep tendon reflexes were exaggerated, she had ankle clonus and extensor plantar reflexes. Cerebellar type dysmetria was present in the limbs and gait was ataxic. ECG, blood and serological tests were normal 


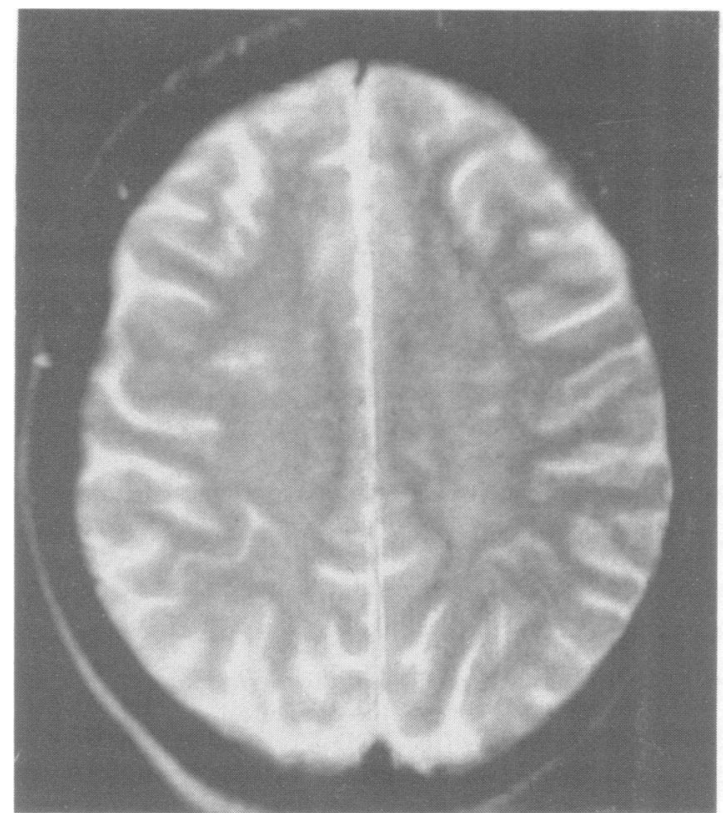

Fig 3 Patient 2. MRI. Patches of increased signal in white matter.

except for slight elevations of liver enzymes (GOT $61 \mathrm{Iu} / 1$, GPT $108 \mathrm{Iu} / 1$, LDH $243 \mathrm{Iu} / \mathrm{l})$ and below normal levels of components of serum complement $\left(C_{2} 28.5 \mu \mathrm{g} / 1, C_{3} 0.91 \mu \mathrm{g} / 1\right.$, $\left.\mathrm{C}_{4} 0 \cdot 16 \mu \mathrm{g} / \mathrm{l}\right)$. ESR was $9 \mathrm{~mm} / \mathrm{h}$. ANA and cold agglutinins were negative. CT showed cortical and cerebellar atrophy and slightly enlarged ventricles. CSF contained 2 lymphocytes, protein was $460 \mathrm{mg} / \mathrm{l}$, glucose was normal, and myelin basic protein was not increased. She gradually worsened and, one year later, had rotatory nystagmus and could not sit up in bed without support and frequently fell when she tried to walk. The CSF contained 6 lymphocytes and a protein content of $259 \mathrm{mg} / \mathrm{l}$. Fluorescein angiography showed leakage of dye from peripapillary arteries and severe sheathing and attenuation of retinal arterioles bilaterally. ESR was $27 \mathrm{~mm} / \mathrm{h}$. ANA was 1:320 and rheumatoid factor was $1 / 160 . C_{3}$ was $1.31 \mu \mathrm{g} / 1$ and $C_{4} 0.32 \mu \mathrm{g} / 1$. Muscle biopsy specimen was normal. She was discharged on prednisone 60 $\mathrm{mg}$ and azathioprine $100 \mathrm{mg}$ daily. Her intellectual function and gait improved, but when the dose of prednisone was tapered to $80 \mathrm{mg}$ qod, she became more ataxic. One year later, she worsened despite a boost in prednisone and azathioprine dosage. CT showed further cerebral and cerebellar atrophy and larger ventricles. ANA was 1:16 and anti SS-DNA was slightly increased to 4 (normal $0-2.5$ ). Anti-HiV antibodies were negative. Complement levels were slightly decreased $\left(\mathrm{C}_{3} 30.67 \mu \mathrm{g} / 1, \mathrm{C}_{4} 0.13 \mu \mathrm{g} / \mathrm{l}, \mathrm{CH} 50\right.$ 92). She was given six large volume plasmaphereses and begun on oral cyclophosphamide. Despite this treatment, she continued to deteriorate. Azathioprine replaced cyclophosphamide, and prednisone was gradually tapered. MRI showed prominent atrophy and altered white matter signals. Ten years after onset, she is severely demented, immobile, incontinent and functionally blind and deaf.

\section{Discussion}

Our patients showed an association of diffuse encephalopathy, retinal obstructions and hearing loss, in the absence of evidence for systemic disease despite extensive investigations. This condition is similar to that described in 1979 by Susac et al. ${ }^{2}$ in two young women (aged 26 years and 40 years), in whom the psychic disturbances overshadowed initially neurologic signs. Both of them had multifocal branch retinal artery occlusions. They also had hearing loss, but this was not emphasised by the authors, who called this condition "microangiography of the brain and retina". Six years later, Pfaffenbach and Hollenhorst ${ }^{1}$ had reported the cases of two young women (aged 38 years), who had dementia, long-tract signs and multifocal retinal artery branch occlusions with areas of infarction. These abnormalities were attributed by the authors to systemic lupus erythematosus, but no clinical or laboratory support for this diagnosis was present. Occlusive retinal vascular disease and deafness was mentioned by others, but without further

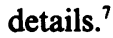

More recently, eight further North American patients have been reported. ${ }^{3-6}$ All four were young (21 to 33 years) women, who had encephalopathy, retinal arteriolar occlusions with infarcts, and cochlear hypoacousia. Extensive laboratory investigations remained negative, except for elevated proteins in the CSF. Increased CSF proteins, slightly elevated ESR and weakly positive ANA with slightly decreased complement fractions are the sole biologic (abnormalities to be reported in some of the cases from the literature (and in our patients 1 and 3); other immunological tests were always negative. Nevertheless, an angiitic form of vasculopathy was postulated, ${ }^{2}$ because cerebral angiography showed segmental narrowing in one, patient, and "sclerosis of small pial and cortical vessels consistent with "healed" "angiitis" on brain biopsy performed in another patient after 3 months under steroid therapy. However, cerebral angiography was normal in other patients $(3,4$ and our patient 1). Non-specific changes were also found at brain biopsy in two cases (case 2 of Susac $^{2}$ and our patient 1). MRI showed multiple areas of increased signal on $\mathrm{T}_{2}$-weighted images in case 2 of Monteiro et al. ${ }^{4}$ and in our second and third patients.

Apart from increased CSF proteins and moderately elevated ESR, our first patient had abnormalities of $T$ helper and suppressor cells in blood (increased Leu 3a/ Leu 2a ratio, decreased Leu 7), which may suggest an immunological dysfunction, despite all other negative results. Yet the pathogenesis of this retinocochleocerebral arteriolopathy remains obscure, and selective involvement of young women is unexplained. Because of possible immunological dysfunction, 
immunosuppressive therapy with steroids or cyclophosphamide has been proposed, with apparent improvement..$^{2-4}$ Our first patient improved while on prednisone and azathioprin therapy, but our second patient made a significant recovery without any therapy. The third patient worsened considerably despite immunosuppressive therapy. Although it may seem appropriate to give steroids in the acute presenting phase, a benefit from prolonged immunosuppressive therapy is not established.

Although the pathogenesis of this retinocochleocerebral arteriolopathy is undetermined, its unique clinical features suggest strongly that it is a distinct disease. It is a rare condition, but one of the reasons may be that it is unrecognised. Description and study of further patients is mandatory to improve knowledge of pathogenesis and treatment strategy.

We thank L Zografos, MD, A Uske, MD, A Steck, $M D$, and $O$ Joyeux, MD, for their help in the study of the patients.

Addendum: Since this paper was accepted for publication, two Finnish patients have been reported. Reference:
Heiskala $\mathrm{H}$, Somer $\mathrm{H}$, Koranen J et al. Microangiopathy with encephalopathy, hearing loss and retinal arteriolar occlusions: two new cases. J Neurol Sci 1988;86:239-50.

\section{References}

1 Pfaffenbach DP, Hollenhorst RW. Microangiopathy of the retina. JAMA 1973;225:480-3.

2 Susac JO, Hardman JM, Selhorst JB. Microangiopathy of the brain and retina. Neurology 1979;29:313-6.

3 Coppeto JR, Currie JN, Monteiro MLR, Lessell S. A syndrome of arterial-occlusive retinopathy and encephalopathy. Am J Ophthalmol 1984;98:189-202.

4 Monteiro MLR, Swanson RA, Coppeto JR, Cuneo RA, De Armond SJ, Prusiner SB. A microangiopathic syndrome of encephalopathy, hearing loss and retinal arteriolar occlusions. Neurology 1985;35:1113-21.

5 McFadyen DJ, Schneider RJ, Chisholm IA. A syndrome of brain, inner leer and retinal microangiopathy. Can J Neurol Sci 1987;14:315-318.

6 Mass M, Bourdette D, Bernstein W, Hammerstad J. Retinopathy, encephalopathy, deafness associated microangiopathy (the RED M syndrome): three new cases. Neurology 38(Supp 1):215,1988.

7 Delaney WV, Torris PF. Occlusive retinal vascular disease and deafness. Am J Ophthalmol 1976;82: 232-236. 